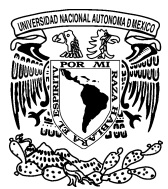

\title{
Revelación de informaciones sobre capital estructural organizativo de los bancos en Brasil y España
}

\section{Disclosure of information on organizational structural capital banks in Brazil and Spain}

\author{
Edila Eudemia Herrera Rodríguez ${ }^{\mathrm{a}, *}$ y Clea Beatriz Macagnan ${ }^{\mathrm{b}}$ \\ a Universidad de Panamá, República de Panamá \\ b Universidade do Vale Do Rio Dos Sinos, Brasil
}

Recibido el 8 de agosto de 2014; aceptado el 10 de marzo de 2015

Disponible en Internet el 28 de octubre de 2015

\section{Resumen}

El estudio analiza las características que motivan la revelación voluntaria sobre intangibles representativos de capital estructural organizativo de las organizaciones bancarias inscritas en las bolsas de valores: de Brasil y España. La contabilidad tradicional no se acerca al valor real de las organizaciones, obtenido por su capital intangible. Para mitigar la marcada diferencia entre el valor contable y el precio de mercado de estas organizaciones, ha surgido la tendencia a revelar informaciones voluntarias sobre sus recursos intangibles. La asimetría de la información, resultante de la no contabilización de los recursos estructurales organizativos, es estudiada por 2 perspectivas teóricas. La teoría de la agencia sugiere que la revelación voluntaria de informaciones reduce los costes de agencia. La teoría del coste del propietario presupone que revelar informaciones genera costes adicionales, así como la posibilidad de pérdida de sus ventajas competitivas. Esta investigación examina 174 informes anuales de 29 bancos, del 2006 al 2011. Se utilizó la técnica de regresión lineal múltiple, a través del método de mínimos cuadrados con datos de panel. Los resultados confirman las hipótesis de que los bancos de mayor tamaño, los más rentables y los más

\footnotetext{
* Autora para correspondencia.

Correo electrónico: eherreradeleon@ hotmail.com (E.E. Herrera Rodríguez).

La revisión por pares es responsabilidad de la Universidad Nacional Autónoma de México.
} 
antiguos, están más motivados a revelar voluntariamente informaciones representativas de capital estructural organizativo.

Derechos Reservados (? 2015 Universidad Nacional Autónoma de México, Facultad de Contaduría y Administración. Este es un artículo de acceso abierto distribuido bajo los términos de la Licencia Creative Commons CC BY-NC-ND 4.0.

Palabras clave: Revelación voluntaria; Capital estructural organizativo; Asimetría de información; Teoría de la agencia; Teoría del coste del propietario

\begin{abstract}
The study analyzes the characteristics that motivate the voluntary disclosure on intangible representing organizational structural capital of the banking organizations registered on stock exchanges: Brazil and Spain. Traditional accounting is not approaching the real value of the organizations, obtained by its intangible capital. To mitigate the marked difference between the book value and the market price of these organizations, the trend to voluntary disclosures on their intangible resources has emerged. The asymmetry of information, resulting from not accounting for the organizational structural resources is studied by 2 theoretical perspectives. Agency theory suggests that the voluntary disclosure of information reduces agency costs. The theory of the cost of the owner assumes that reveal information generates additional costs, as well as the possibility of loss of its competitive advantages. This research examines 174 annual reports of 29 banks, from 2006 to 2011. The technique of multiple linear regressions using the method of least squares with panel data was used. The test results confirm the hypothesis that large banks, the most profitable and the oldest are more motivated to voluntarily disclose information representing organizational structural capital.

All Rights Reserved (C) 2015 Universidad Nacional Autónoma de México, Facultad de Contaduría y Administración. This is an open access item distributed under the Creative Commons CC License BY-NC-ND 4.0.

Keywords: Voluntary disclosure; Organizational structural capital; Asymmetry of information; Agency theory; Theory of the cost of the owner
\end{abstract}

\title{
Introducción
}

La existencia de asimetría de información entre agentes y propietarios impide que las transacciones en el mercado de capitales se desarrollen de forma eficiente. Un papel fundamental de la información contable en los mercados financieros es servir como una base para la asignación de capital (Bhattachrya, Desai y Venkataraman, 2013). En este sentido, la tendencia de los agentes estaría entonces dirigida a revelar mayores informaciones a fin de atraer el capital de los inversionistas para financiarse. Esto debido el hecho de que los problemas de información y de la agencia pueden reducir la capacidad de las empresas para acceder a financiación externa y da lugar a limitaciones financieras (Gopalan, Udell y Yerramilli, 2011). La revelación de informaciones voluntarias en los informes anuales ha surgido como mecanismo para reducir el problema de la asimetría de la información. Todo esto debido a que la contabilidad tradicional no permite revelar este tipo de informaciones porque la norma contable se encuentra limitada a revelar el valor contable al costo. Así, se mantiene una marcada diferencia entre el valor contable y el valor de mercado de las organizaciones. A través de la revelación voluntaria de informaciones por parte de los gestores de las organizaciones, los interesados pueden tener un mecanismo para conocer aspectos adicionales de las organizaciones, que no son exigidos por las normas legales. 
Esta investigación se basa en 2 teorías: la teoría de la agencia y la teoría del coste del propietario. Según los presupuestos de la teoría de la agencia, existen ventajas en la revelación de información, como la eficiencia en la toma de decisiones por parte de los agentes y el control de los directivos (Jensen y Meckling, 1976). Por otra parte, pudieran surgir desventajas como los costes de procesar y publicar las informaciones, así como la posible pérdida de ventajas competitivas por estar revelando información estratégica a la competencia, según la teoría del coste del propietario (Verrecchia, 1983; Fishman y Hagerty, 1989; Darrough y Stoughton, 1990; Wagenhofer, 1990; Macagnan, 2007).

La relevancia de este estudio ha sido reconocida por el Banco Mundial que ha financiado el mismo, lo que muestra el marcado interés de parte de organismos internacionales de prestigio por el desarrollo de este tipo de investigaciones. A partir de la crisis económica de la década de 2000 , con el problema con la quiebra de grandes corporaciones como el caso Enron, Tyco, WorldCom, entre otros, surgió la necesidad de una mayor transparencia en cuanto al comportamiento bancario. Así surge el marco internacional regulador para bancos (Basilea). En el 2010 fue propuesto por el Comité de Supervisión Bancaria de Basilea, el Convenio Basilea III, a fin de lograr la medición, normalización y seguimiento del riesgo de liquidez a nivel internacional.

La normativa internacional, buscando responder a la cantidad de fraudes, estaría enfocada a que el propósito de la empresa sea maximizar el valor para el accionista. De esta forma, el objeto de la junta directiva estaría orientado a garantizar que la maximización del valor del accionista predomine sobre los intereses ejecutivos (Fama y Jensen, 1983; Hermalin y Weisbach, 2003; Joseph, Ocasio y McDonnell, 2014). En este sentido surge el gobierno corporativo, orientado hacia el hecho de que las organizaciones reflejen más responsabilidad y transparencia con los accionistas (Adiloğlu y Vuran, 2012). Esta serie de mecanismos en cuanto a gobernanza han sido postulados para mitigar de forma efectiva el problema de agencia (Dalton, Hitt, Certo y Dalton, 2007; Eisenhardt, 1989; Shleifer y Vishny, 1997; Misangyi y Acharya, 2014). El uso de incentivos para crear la alineación entre los principales y agentes es un mecanismo primario propuesto por la teoría de la agencia (Gómez-Mejía, Berrone y Franco-Santos, 2010; CuevasRodríguez, Gómez-Mejía y Wiseman, 2012), considerándose un factor influyente en cuanto al buen gobierno corporativo (Clegg, 2010; Lan y Heracleous, 2010; Cuevas-Rodríguez et al., 2012; Raelin y Bondy, 2013).

Este estudio analiza las características que motivan la revelación voluntaria sobre intangibles representativos de capital estructural organizativo de las organizaciones bancarias inscritas en las bolsas de valores: de Brasil y de España. Fueron seleccionados los bancos de Brasil, ya que integra el grupo BRICS, que presenta un gran crecimiento en el comercio mundial, constituyéndose como un país atractivo como destino de inversiones. Los bancos españoles fueron seleccionados para establecer una comparación con un país europeo y que mantuviera semejanzas de mercado.

En Brasil fue seleccionada la bolsa de São Paulo-BM\&F BOVESPA y en España las bolsas de Madrid y Barcelona. Del total de los bancos registrados en las respectivas bolsas de valores, fueron seleccionados aquellos que publicaron el $100 \%$ de sus informes anuales en la página de Internet durante el período 2006-2011. A partir la revisión de los informes anuales, fueron contrastadas las siguientes hipótesis: el tamaño, la rentabilidad, el endeudamiento, la antigüedad, el precio de la acción dividido por el valor contable, el pago de dividendos, la emisión de nuevas acciones, el dividendo por acción, la cotización en más de una bolsa y el crecimiento como características explicativas del nivel de revelación de los recursos intangibles de los bancos que cotizan en mercados de capitales de Brasil y/o de España.

Se utilizó un índice de divulgación, que es un indicador numérico que mide la cantidad de información divulgada por la empresa. Este índice estuvo representado por 19 indicadores, todos 
ellos voluntarios, representativos del capital estructural organizativo. Cada indicador toma el valor de uno si el banco divulga información respecto al indicador y cero en caso contrario. El resto de este estudio está estructurado de la siguiente manera. La segunda sección presenta la revisión de la literatura, donde se analizan investigaciones que han revisado el tema de la revelación voluntaria de recursos intangibles, bajo las premisas de la teoría de la agencia y la teoría del coste del propietario. En la tercera sección se presenta la formulación de hipótesis de esta investigación. Seguidamente se presenta la metodología, donde se explica todo el proceso utilizado para el desarrollo de este estudio. La quinta parte presenta los resultados que concluyen esta investigación Finalmente se exponen las consideraciones finales de este estudio, los aportes, las limitaciones y las futuras líneas de investigación.

\section{Revisión de la literatura}

La revelación de información voluntaria sobre recursos intangibles es una práctica que ha logrado auge entre las organizaciones actuales. Se trata de una práctica empresarial cada vez más común, debido a los beneficios derivados de ella. (Rodríguez, Gallego y García, 2008). En los últimos años, la revelación de información por parte de las empresas ha ganado mayor atención debido a la globalización, una mayor integración de los mercados de capitales, mayor movilidad monetaria y de bienes reales, mayor competencia, desarrollo de nuevas industrias e Internet (Bukh, Nielsen, Gormsen y Mouritsen, 2005). La revelación de este tipo de informaciones difiere para cada uno de los países. Esta revelación presenta ventajas por una parte, mientras que por otra pudiera conducir a desventajas y consecuencias poco favorables.

Las presiones del mercado podrían estar motivando a las organizaciones a revelar informaciones adicionales sobre sus recursos intangibles. La capacidad de los empresarios para encontrar financiación estaría limitada por la presencia de costes de agencia en los mercados de capitales (Fulghieri y Suominen, 2012). Normalmente los reguladores del mercado financiero establecen las normas sobre las informaciones mínimas que deben se reveladas (Subramanian y Nagi, 2010). En este sentido, la divulgación de información financiera de un país sería determinada en función no solo de los requisitos reglamentarios y el grado de cumplimiento, sino también de las presiones del mercado para cumplir con la divulgación (Camfferman y Cooke, 2002; Kang y Gray, 2011). Esto porque el crecimiento de las necesidades de información de los inversionistas y la complejidad del mercado afectarían tanto el volumen como la calidad de la información divulgada (Boesso y Kumar, 2007). Para facilitar el acceso al mercado de capitales, las empresas deben proveer a sus accionistas y a los potenciales proveedores de capital la garantía de que sus intereses serán protegidos (Ferraz, Fernandes y Louvet, 2011). Se trataría no solamente de revelar informaciones, se requeriría además informar sobre aquellos aspectos relevantes, que pudieran servir de herramienta para aquellos que tendrían intereses en el desempeño de las organizaciones en el mercado. Todo ello estaría encaminado a la reducción de la asimetría de la información.

El tema de la asimetría de la información ha sido abordado por Akerlof (1970) en su estudio sobre la calidad y la incertidumbre en el mercado automotriz. Partiendo del hecho de que la asimetría de la información ocurriría cuando una de las partes posee más información que la otra, Akerlof (1970) utiliza el mercado automotriz para ilustrar y desarrollar sus pensamientos, a través de la venta de autos usados. El autor señala que los clientes en este mercado compran un automóvil sin saber si el mismo es bueno o malo. Surgiría aquí el problema de la asimetría de la información, en vista de que los vendedores podrían contar con más información que los compradores. Dado el caso de contar con información incompleta, podría darse la situación que resultaría en beneficio de una de las partes involucradas en la transacción, en detrimento de su 
contraparte. Por consiguiente, sería de suponer que aquellos mejor informados tomarían mejores decisiones, y en detrimento de los menos informados, quienes probablemente sufrirían pérdidas, lo cual afectaría la eficiencia del mercado (Macagnan, 2007).

La teoría de la agencia presenta las ventajas de la revelación de información, argumentando que reduciría la asimetría de la información y los costes de agencia. Esto debido a que esta teoría predice el conflicto de intereses entre los gerentes y los accionistas, provocando problemas de agencia; surgidos por el hecho de que los administradores busquen satisfacer sus propios beneficios en lugar trabajar en beneficio de los accionistas de la empresa (Jensen y Meckling, 1976). Se trata de la posibilidad de que el agente económico tome decisiones a favor de sus intereses, contrariando los intereses del principal, que lo ha contratado (Gazda, Maliková, Kubák y Gróf, 2012). Esto surgiría del hecho de que el agente tomaría decisiones sobre una inversión privada (Gershkov y Perry, 2012). Las medidas para controlar las referidas situaciones generarían costes, denominados costes de agencia (Jensen y Meckling, 1976): a) gastos del principal, generados por la vigilancia de las actuaciones del agente (gastos de control o vigilancia), a fin de garantizar que el agente actuará en beneficio de sus intereses; b) costes incurridos por el agente (gastos de garantía), en el sentido de demostrar que estaría actuando en beneficio de los intereses del principal; y c) la pérdida residual: las divergencias que se darán entre los resultados conseguidos y los que hubiera conseguido el principal por actuar directamente. La revelación de información corporativa podría ayudar para el buen funcionamiento de los mercados de capitales (Healy y Palepu, 2001), ya que mejoraría la imagen de la empresa, con el incremento de la confianza por parte de los inversores (Babío, Muíño y Vidal, 2003). Además de ello, existiría la posibilidad de obtener mayores volúmenes de fondos (Marr y Gray, 2002; Lev, 2004), favoreciendo la reducción del coste de capital (Easley y O'Hara, 2005).

En cuanto a las desventajas de la revelación voluntaria de información, la teoría del coste del propietario (Verrecchia, 1983; Cooke, 1989; Fishman y Hagerty, 1989; Wagenhofer, 1990; Darrough y Stoughton, 1990; Cooke, 1992; Prencipe, 2004; Macagnan, 2007) plantea los presupuestos de que revelar informaciones generaría costes por procesar las informaciones, así como posibilitaría la pérdida de ventajas competitivas. Estas desventajas, en ocasiones, podrían superar los beneficios citados (Gray, Radebaugh y Roberts, 1990). Los directivos limitarían la revelación de información voluntaria de las organizaciones, cuando presentan costes de propiedad (Prencipe, 2004). Por otro lado, a medida que los competidores tuvieran informaciones sobre la posición estratégica de la organización, podrían reaccionar desarrollando estrategias alternativas (Macagnan, 2007). Todo ello, porque la revelación de información posibilita una acción adversa de la competencia (Wagenhofer, 1990; Darrough y Stoughton, 1990). Estos costes permitirían comprender las razones por las cuales las organizaciones no presentarían información sobre recursos intangibles. Por tanto, la revelación de información se podría reducir, como una acción discreta para no afectar así los costes de propiedad (Wagenhofer, 1990).

\section{Formulación de hipótesis}

Seguidamente se presentan las hipótesis a contrastar en esta investigación, sobre las posibles características que motivan la revelación voluntaria sobre intangibles representativos de capital estructural organizativo de las organizaciones bancarias. En base a una amplia revisión de literatura, se han formulado las hipótesis tamaño, rentabilidad, endeudamiento, antigüedad, precio de la acción entre su valor contable, pago de dividendos, emisión de nuevas acciones, dividendos por acción, cotización en más de una bolsa y crecimiento. 
Las organizaciones de mayor tamaño tienen actividades y estructuras organizativas más complejas que las empresas pequeñas, además de requerir en mayor medida del mercado de capitales para financiarse (Singhvi y Desay, 1971). Este último aspecto acaba condicionando especialmente la cantidad y calidad de la información a revelar (Rodríguez et al., 2008). Las grandes compañías tienen mayor cobertura en los mercados de capitales, por lo que son objeto de mayores análisis por parte de aquellos que participan en estos mercados. Por ello existiría la presión por parte de un mayor número de usuarios que exigirían mayor cantidad de informaciones.

En este sentido, la teoría de la agencia (Jensen y Meckling, 1976) apunta al hecho de que el tamaño sería una característica de los bancos para aumentar la revelación de informaciones sobre su capital estructural organizativo, con el fin de disminuir los conflictos de intereses entre agentes y propietarios, reduciendo así el problema de la asimetría de la información.

En un sentido opuesto, la teoría del coste del propietario (Verrecchia, 1983, Macagnan, 2007) presupone que revelar informaciones adicionales genera costes para procesar y publicar estas informaciones (Buzby, 1975; Cooke, 1989, 1992). Además de ello, existiría la posibilidad de que la competencia obtenga ventaja al conocer ventajas competitivas de las organizaciones, por revelar informaciones estratégicas a la competencia (Macagnan, 2007).

Según la teoría de la agencia (Jensen y Meckling, 1976), los agentes de las empresas más rentables podrían tener la tendencia a revelar mayor cantidad de informaciones sobre sus recursos intangibles. De esta manera justificarían su situación financiera ante los accionistas. El fin de esto sería establecer mejores condiciones contractuales en su relación con los propietarios. Cuando el margen de beneficio neto es alto, los directivos podrían revelar mayor información para informar a los accionistas sobre la posición financiera, así como posiblemente beneficiarse a sí mismos en términos de compensación de gestión adicional (Singhvi y Desay, 1971).

Las organizaciones con baja rentabilidad serían más propensas a suministrar más información, con el fin de justificarse ante los accionistas (Macagnan, 2007). Tomando en consideración la teoría del coste del propietario (Verrecchia, 1983; Macagnan, 2007), se esperaría que una empresa con buenos resultados estuviera menos predispuesta a revelar información sobre sus recursos intangibles, ya que podría estar ofreciendo a la competencia información que podría ser copiada (Macagnan, 2007).

El endeudamiento de la empresa podría indicar que la organización estaría proyectando inversiones, que le permitirían crecer e incrementar sus utilidades. En este sentido, revelar informaciones sobre recursos intangibles, para justificar las inversiones de capital, reduciría la asimetría de la información, estableciendo la confianza en la gestión de los recursos de la organización (Macagnan, 2007).

La teoría de la agencia (Jensen y Meckling, 1976) podría explicar la relación positiva entre el endeudamiento y revelación de información sobre recursos intangibles. De acuerdo con esta teoría, las organizaciones muy endeudadas tendrían un incentivo para incrementar el nivel de información a las partes interesadas, para justificar el uso que le estarían dando a sus recursos.

De acuerdo a los presupuestos de la teoría de la agencia (Jensen y Meckling, 1976), cuanto más tiempo de existencia tenga la empresa, mayor debería ser la revelación de información sobre recursos intangibles. Las organizaciones con más años de existencia podrían brindar a los accionistas mayor confianza a la hora de invertir en ellas, debido a la solidez que posiblemente reflejan. Lo contrario ocurre con las organizaciones nuevas. Por lo tanto, las organizaciones jóvenes requerirían revelar más informaciones sobre recursos intangibles, debido al grado de incertidumbre que las mismas pudieran reflejar (Macagnan, 2007). En base al presupuesto de la teoría del coste del propietario (Verrecchia, 1983, Macagnan, 2007), cuantos más años lleve 
constituida la empresa estaría mostrando su trayectoria, por lo que revelar información de este tipo sería incurrir en gastos innecesarios.

La teoría de la agencia (Jensen y Meckling, 1976) plantea que cuanto mayor sea el precio de la acción dividido entre el valor contable, mayor debería ser la revelación de información sobre recursos intangibles. De esta forma se reduciría el problema de la asimetría de la información. Las organizaciones tratarían de minimizar los conflictos de intereses con los inversionistas. Así justificarían que la diferencia entre el valor contable y el valor de mercado estaría compuesta por recursos intangibles no contabilizados. Al dividir el precio de la acción entre su valor contable, se podría obtener una visión del valor de las acciones en el mercado, lo cual ofrecería a los inversionistas la oportunidad de identificar aquellas acciones minusvaloradas, que pudieran resultar como alternativas de inversión. Desde otra perspectiva, la teoría del coste del propietario (Verrecchia, 1983; Macagnan, 2007) plantea que la propia valoración de las acciones en el mercado habla por sí sola de la situación de la empresa, por lo que no sería necesario incurrir en este tipo de costes.

La política de pago de dividendos sería una decisión compleja. Por ello, se deben considerar, entre otros aspectos, las necesidades de los inversores, pero también las oportunidades de crecimiento interno de la empresa y las fuentes de flujo de efectivo (Hyderabad, 2013). Informar sobre el pago de dividendos podría generar confianza entre los inversionistas actuales y aquellos potenciales, ya que esto sería una señal de que la organización genera recursos y que tendría la solidez necesaria para hacer frente a sus compromisos financieros. De esta manera, los accionistas tendrían una estimación de los beneficios que podrían recibir en el futuro, por el capital invertido. En base a estos presupuestos, la teoría de la agencia (Jensen y Meckling, 1976) indicaría que la administración está centrada en los intereses de los inversionistas. Por su parte, la teoría del coste del propietario (Verrecchia, 1983; Macagnan, 2007) plantearía que el propio pago de dividendos reflejaría la solidez financiera de la organización, mostrando que trabaja por los intereses de los accionistas. Por esto, no sería necesario incurrir en costos adicionales, por generar informaciones sobre estos pagos.

La emisión de nuevas acciones podría ser un indicativo del crecimiento de la organización. Con esto, el inversionista podría deducir que la organización contaría con la credibilidad necesaria para tomar la decisión de invertir sus recursos en ella. La teoría de la agencia (Jensen y Meckling, 1976), en este caso, plantearía que a medida que las organizaciones revelen más información acerca de las nuevas acciones emitidas, más confianza generarían en el mercado. Por consiguiente, atraerían a más inversores que buscarían obtener beneficios a través de sus acciones y participaciones. Por otra parte, revelar informaciones sobre la emisión de nuevas obligaciones implicaría costes adicionales para la organización, según la teoría del coste del propietario (Verrecchia, 1983; Macagnan, 2007).

En base a los presupuestos de la teoría de la agencia, a través de la divulgación de los dividendos generados por acción la organización demostraría su capacidad de gestión de los recursos de los accionistas. Además, estaría reflejando el hecho de que trabaja por los intereses de quienes se convierten en proveedores de capital. Con ello estaría reduciendo los costes de agencia (Jensen y Meckling, 1976). Según los presupuestos de la teoría del coste del propietario (Verrecchia, 1983; Macagnan, 2007) revelar informaciones sobre el pago de dividendos generaría costes innecesarios, en vista de que los propios dividendos pagados por acción serían una señal de la situación financiera de la organización.

Una organización que cotiza en más de una bolsa debería revelar más informaciones sobre recursos intangibles según la teoría de la agencia (Jensen y Meckling, 1976), debido a que más inversionistas de diferentes partes del mundo, esperarían información que les pudieran permitir tomar las decisiones más acertadas respecto a dónde invertirían sus recursos financieros; además de la existencia de mayor cantidad de contratos (Macagnan, 2007). Por otro lado, el solo hecho de 
cotizar en más de una bolsa de valores hablaría propiamente de la expansión de la organización hacia otros mercados. Por esto, podría no ser necesario incurrir en costes adicionales de revelar informaciones sobre este tipo de intangibles, según los presupuestos de la teoría del coste del propietario (Verrecchia, 1983; Macagnan, 2007).

Según los presupuestos de la teoría de la agencia (Jensen y Meckling, 1976), en la medida en que las empresas crecen, deberían revelar mayores informaciones a los interesados, debido a la gran cantidad de contratos, situación que podría generar conflictos de intereses entre agentes y propietarios (Macagnan, 2007). Con ello se incrementaría el problema de la asimetría de información, y por ende los costes de agencia. Una alternativa para reducir estos costes de agencia podría ser revelar más informaciones sobre recursos intangibles. Por otro lado, la teoría del coste del propietario (Verrecchia, 1983; Macagnan, 2007) indicaría que las organizaciones que estuvieran en crecimiento podrían sufrir costos por revelar informaciones. Adicional a ello, estarían revelando informaciones a la competencia sobre sus ventajas competitivas (Macagnan, 2007).

En base a estos planteamientos se formulan las hipótesis de esta investigación en la tabla 1. También se presentan las investigaciones que han contrastados las mismas, los países respectivos, el tipo de industria y la relación encontrada.

La relación positiva de las variables explicativas es medida en base a que cuanto mayor sea el tamaño de las mismas, mayor será la motivación de la revelación de informaciones representativas del capital estructural organizativo. La relación negativa, en cambio, indica que cuanto mayor sea el tamaño de la variable explicativa, menor será la motivación para revelar este tipo de informaciones.

\section{Metodología}

Este estudio analiza las características que motivan la revelación voluntaria sobre intangibles representativos de capital estructural organizativo de las organizaciones bancarias inscritas en las bolsas de valores: de Brasil y de España. Para ello se construyó un índice con 19 indicadores a fin de medir la revelación voluntaria de informaciones del capital estructural organizativo de las organizaciones bancarias. Este índice constituye la variable dependiente y lo representan aquellos indicadores, todos revelados de forma voluntaria, como la estrategia de la empresa, la cultura, estructuras y sistemas y rutinas organizacionales, es decir todo aquello que pudiera ayudar a almacenar y distribuir el conocimiento. Se trata de la capacidad de administrar el capital humano. Están representados por indicadores tales como sistemas y procesos, estructura organizacional, bases de datos y demás aspectos relacionados con la estructura organizacional de la empresa.

Estos indicadores fueron construidos a partir del modelo Macagnan (2007). Macagnan utilizó 20 indicadores para analizar los condicionantes de la revelación de activos intangibles en diferentes empresas que cotizan el mercado de capitales de España (bolsas de valores de Madrid y Barcelona). En el anexo 1 se presentan los indicadores de capital estructural organizativo de esta investigación.

Para calcular el nivel de revelación, variable dependiente, se utilizó el índice de divulgación Ij, que está basado en el enfoque dicotómico (Cooke, 1989, 1992; Camfferman y Cooke, 2002; Macagnan, 2007, 2009) y se define como:

$$
I j=\frac{\sum_{i=1}^{n j} \chi_{i j}}{n j}
$$


Tabla 1

Hipótesis, relación estimada e investigaciones similares

\begin{tabular}{|c|c|c|c|c|c|}
\hline Investigaciones & País & Tipo de industria & Hipótesis & $\begin{array}{l}\text { Relación } \\
\text { estimada }\end{array}$ & $\begin{array}{l}\text { Relación } \\
\text { encontrada }\end{array}$ \\
\hline Carnaghan, 1999 & Canadá & $\begin{array}{l}\text { Empresas de ID } \\
\text { cotizadas en la bolsa } \\
\text { de valores de Toronto }\end{array}$ & Tamaño & + & + \\
\hline $\begin{array}{l}\text { Gray, Javad, Power y } \\
\text { Sinclair (2001) }\end{array}$ & Reino Unido & 100 empresas top & & & + \\
\hline Arvidsson (2003) & $\begin{array}{l}\text { Dinamarca, } \\
\text { Finlandia, } \\
\text { Suecia y } \\
\text { Noruega }\end{array}$ & $\begin{array}{l}\text { Industria } \\
\text { farmacéutica, } \\
\text { biotecnología }\end{array}$ & & & + \\
\hline $\begin{array}{l}\text { Bozzolan, Favotto y } \\
\text { Ricceri (2003) }\end{array}$ & Italia & $\begin{array}{l}\text { Compañías listadas en } \\
\text { bolsa }\end{array}$ & & & + \\
\hline Rodríguez (2004) & España & Manufactura & & & + \\
\hline $\begin{array}{l}\text { García-Meca, Parra, } \\
\text { Larrán y Martínez } \\
\text { (2005) }\end{array}$ & España & $\begin{array}{l}\text { Empresas listadas en } \\
\text { bolsa }\end{array}$ & & & + \\
\hline Macagnan (2005) & España & $\begin{array}{l}\text { Empresas listadas en } \\
\text { las bolsas de Madrid y } \\
\text { Barcelona (varios } \\
\text { sectores) }\end{array}$ & & & + \\
\hline $\begin{array}{l}\text { Macagnan y } \\
\text { Rodríguez (2005) }\end{array}$ & España & $\begin{array}{l}\text { Empresas listadas en } \\
\text { las bolsas de Madrid y } \\
\text { Barcelona (varios } \\
\text { sectores) }\end{array}$ & & & + \\
\hline Macagnan (2007) & España & $\begin{array}{l}\text { Empresas listadas en } \\
\text { las bolsas de Madrid y } \\
\text { Barcelona (varios } \\
\text { sectores) }\end{array}$ & & & + \\
\hline Macagnan (2009) & España & $\begin{array}{l}\text { Empresas listadas en } \\
\text { las bolsas de Madrid y } \\
\text { Barcelona (varios } \\
\text { sectores) }\end{array}$ & & & + \\
\hline Fontana (2011) & Brasil & $\begin{array}{l}\text { Empresas listadas } \\
\text { BOVESPA }\end{array}$ & & & - \\
\hline Vikalpa (2012) & $\begin{array}{l}\text { India, Estados } \\
\text { Unidos y } \\
\text { Japón }\end{array}$ & $\begin{array}{l}\text { Varios tipos de } \\
\text { industria }\end{array}$ & & & + \\
\hline $\begin{array}{l}\text { Fontana y Macagnan } \\
\qquad(2013)\end{array}$ & Brasil & $\begin{array}{l}\text { Empresas listadas } \\
\text { BOVESPA (varios } \\
\text { sectores) }\end{array}$ & & & - \\
\hline Herrera (2013) & $\begin{array}{l}\text { Brasil y } \\
\text { España }\end{array}$ & Bancos & & & \\
\hline Rodríguez (2004) & España & Manufactura & Rentabilidad & + & + \\
\hline Macagnan (2005) & España & $\begin{array}{l}\text { Empresas listadas en } \\
\text { las bolsas de Madrid y } \\
\text { Barcelona (varios } \\
\text { sectores) }\end{array}$ & & & - \\
\hline $\begin{array}{l}\text { Macagnan y } \\
\text { Rodríguez (2005) }\end{array}$ & España & $\begin{array}{l}\text { Empresas listadas en } \\
\text { las bolsas de Madrid y } \\
\text { Barcelona (varios } \\
\text { sectores) }\end{array}$ & & & - \\
\hline
\end{tabular}


Tabla 1 (Continuación)

\begin{tabular}{|c|c|c|c|c|c|}
\hline Investigaciones & País & Tipo de industria & Hipótesis & $\begin{array}{l}\text { Relación } \\
\text { estimada }\end{array}$ & $\begin{array}{l}\text { Relación } \\
\text { encontrada }\end{array}$ \\
\hline Macagnan (2009) & España & $\begin{array}{l}\text { Empresas listadas en } \\
\text { las bolsas de Madrid y } \\
\text { Barcelona (varios } \\
\text { sectores) }\end{array}$ & & & - \\
\hline Fontana (2011) & Brasil & $\begin{array}{l}\text { Empresas listadas } \\
\text { BOVESPA (varios } \\
\text { sectores) }\end{array}$ & & & - \\
\hline Vikalpa (2012) & $\begin{array}{l}\text { India, Estados } \\
\text { Unidos y } \\
\text { Japón }\end{array}$ & $\begin{array}{l}\text { Varios tipos de } \\
\text { industria }\end{array}$ & & & + \\
\hline Herrera (2013) & $\begin{array}{l}\text { Brasil y } \\
\text { España }\end{array}$ & Bancos & & & \\
\hline Williams (2001) & Reino Unido & $\begin{array}{l}\text { Varios tipos de } \\
\text { industria }\end{array}$ & Endeudamiento & - & + \\
\hline Arvidsson (2003) & $\begin{array}{l}\text { Dinamarca, } \\
\text { Finlandia, } \\
\text { Suecia y } \\
\text { Noruega }\end{array}$ & $\begin{array}{l}\text { Industria } \\
\text { farmacéutica, } \\
\text { biotecnología }\end{array}$ & & & $\mathrm{S} / \mathrm{R}$ \\
\hline $\begin{array}{l}\text { García-Meca et al. } \\
\text { (2005) }\end{array}$ & España & $\begin{array}{l}\text { Empresas listadas en } \\
\text { bolsa (varios sectores) }\end{array}$ & & & $\mathrm{S} / \mathrm{R}$ \\
\hline Macagnan (2005) & España & $\begin{array}{l}\text { Empresas listadas en } \\
\text { las bolsas de Madrid y } \\
\text { Barcelona (varios } \\
\text { sectores) }\end{array}$ & & & $\mathrm{S} / \mathrm{R}$ \\
\hline $\begin{array}{l}\text { Macagnan y } \\
\text { Rodríguez (2005) }\end{array}$ & España & $\begin{array}{l}\text { Empresas listadas en } \\
\text { las bolsas de Madrid y } \\
\text { Barcelona (varios } \\
\text { sectores) }\end{array}$ & & & $\mathrm{S} / \mathrm{R}$ \\
\hline $\begin{array}{l}\text { Hidalgo y García, } \\
2009\end{array}$ & México & $\begin{array}{l}\text { Empresas cotizadas } \\
\text { en la bolsa mexicana } \\
\text { de valores (varios } \\
\text { sectores) }\end{array}$ & & & $\mathrm{S} / \mathrm{R}$ \\
\hline Macagnan (2007) & España & $\begin{array}{l}\text { Empresas listadas en } \\
\text { las bolsas de Madrid y } \\
\text { Barcelona (varios } \\
\text { sectores) }\end{array}$ & & & + \\
\hline Macagnan (2009) & España & $\begin{array}{l}\text { Empresas listadas en } \\
\text { las bolsas de Madrid y } \\
\text { Barcelona }\end{array}$ & & & + \\
\hline Fontana (2011) & Brasil & $\begin{array}{l}\text { Empresas listadas } \\
\text { BOVESPA (varios } \\
\text { sectores) }\end{array}$ & & & + \\
\hline Vikalpa (2012) & $\begin{array}{l}\text { India, Estados } \\
\text { Unidos y } \\
\text { Japón }\end{array}$ & $\begin{array}{l}\text { Varios tipos de } \\
\text { industria }\end{array}$ & & & $\mathrm{S} / \mathrm{R}$ \\
\hline $\begin{array}{l}\text { Fontana y Macagnan } \\
\text { (2013) }\end{array}$ & Brasil & $\begin{array}{l}\text { Empresas listadas } \\
\text { BOVESPA (varios } \\
\text { sectores) }\end{array}$ & & & + \\
\hline
\end{tabular}


Tabla 1 (Continuación)

\begin{tabular}{|c|c|c|c|c|c|}
\hline Investigaciones & País & Tipo de industria & Hipótesis & $\begin{array}{l}\text { Relación } \\
\text { estimada }\end{array}$ & $\begin{array}{l}\text { Relación } \\
\text { encontrada }\end{array}$ \\
\hline Herrera (2013) & $\begin{array}{l}\text { Brasil y } \\
\text { España }\end{array}$ & Bancos & & & + \\
\hline Macagnan (2007) & España & $\begin{array}{l}\text { Empresas listadas en } \\
\text { las bolsas de Madrid y } \\
\text { Barcelona (varios } \\
\text { sectores) }\end{array}$ & Antigüedad & + & + \\
\hline Macagnan (2009) & España & $\begin{array}{l}\text { Empresas listadas en } \\
\text { las bolsas de Madrid y } \\
\text { Barcelona (varios } \\
\text { sectores) }\end{array}$ & & & + \\
\hline Herrera, 2013) & $\begin{array}{l}\text { Brasil y } \\
\text { España }\end{array}$ & Bancos & & & + \\
\hline Macagnan (2007) & España & $\begin{array}{l}\text { Empresas listadas en } \\
\text { las bolsas de Madrid y } \\
\text { Barcelona (varios } \\
\text { sectores) }\end{array}$ & $\begin{array}{l}\text { Precio de la } \\
\text { acción/Valor } \\
\text { contable }\end{array}$ & + & + \\
\hline Macagnan (2009) & España & $\begin{array}{l}\text { Empresas listadas en } \\
\text { las bolsas de Madrid y } \\
\text { Barcelona (varios } \\
\text { sectores) }\end{array}$ & & & + \\
\hline Fontana (2011) & Brasil & $\begin{array}{l}\text { Empresas listadas } \\
\text { BOVESPA (varios } \\
\text { sectores) }\end{array}$ & & & + \\
\hline Herrera, 2013 & $\begin{array}{l}\text { Brasil y } \\
\text { España }\end{array}$ & Bancos & & & + \\
\hline Macagnan (2007) & Brasil & $\begin{array}{l}\text { Empresas listadas en } \\
\text { las bolsas de Madrid y } \\
\text { Barcelona (varios } \\
\text { sectores) }\end{array}$ & $\begin{array}{l}\text { Pago de } \\
\text { dividendos }\end{array}$ & - & $\mathrm{S} / \mathrm{R}$ \\
\hline Macagnan (2009) & Brasil & $\begin{array}{l}\text { Empresas listadas en } \\
\text { las bolsas de Madrid y } \\
\text { Barcelona (varios } \\
\text { sectores) }\end{array}$ & & & $\mathrm{S} / \mathrm{R}$ \\
\hline Herrera (2013) & $\begin{array}{l}\text { Brasil y } \\
\text { España }\end{array}$ & Bancos & & & - \\
\hline Gelb (2002) & $\begin{array}{l}\text { Estados } \\
\text { Unidos }\end{array}$ & $\begin{array}{l}\text { Empresas no } \\
\text { bancarias }\end{array}$ & $\begin{array}{l}\text { Emisión de nuevas } \\
\text { acciones }\end{array}$ & - & $\mathrm{S} / \mathrm{R}$ \\
\hline Macagnan (2007) & Brasil & $\begin{array}{l}\text { Empresas listadas en } \\
\text { las bolsas de Madrid y } \\
\text { Barcelona (varios } \\
\text { sectores) }\end{array}$ & & & $\mathrm{S} / \mathrm{R}$ \\
\hline Herrera (2013) & $\begin{array}{l}\text { Brasil y } \\
\text { España }\end{array}$ & Bancos & & & $\mathrm{S} / \mathrm{R}$ \\
\hline Fontana (2011) & Brasil & $\begin{array}{l}\text { Empresas listadas } \\
\text { BOVESPA (varios } \\
\text { sectores) }\end{array}$ & $\begin{array}{l}\text { Dividendos por } \\
\text { acción }\end{array}$ & - & $\mathrm{S} / \mathrm{R}$ \\
\hline $\begin{array}{l}\text { Fontana y Macagnan } \\
\text { (2013) }\end{array}$ & Brasil & $\begin{array}{l}\text { Empresas listadas } \\
\text { BOVESPA (varios } \\
\text { sectores) }\end{array}$ & & & $\mathrm{S} / \mathrm{R}$ \\
\hline
\end{tabular}


Tabla 1 (Continuación)

\begin{tabular}{|c|c|c|c|c|c|}
\hline Investigaciones & País & Tipo de industria & Hipótesis & $\begin{array}{l}\text { Relación } \\
\text { estimada }\end{array}$ & $\begin{array}{l}\text { Relación } \\
\text { encontrada }\end{array}$ \\
\hline Herrera (2013) & $\begin{array}{l}\text { Brasil y } \\
\text { España }\end{array}$ & Bancos & & & $\mathrm{S} / \mathrm{R}$ \\
\hline Herrera (2013) & $\begin{array}{l}\text { Brasil y } \\
\text { España }\end{array}$ & Bancos & $\begin{array}{l}\text { Cotización en más } \\
\text { de una bolsa }\end{array}$ & + & + \\
\hline Rodríguez (2004) & España & Manufactura & Crecimiento & + & + \\
\hline Fontana (2011) & Brasil & $\begin{array}{l}\text { Empresas listadas } \\
\text { BOVESPA (varios } \\
\text { sectores) }\end{array}$ & & & + \\
\hline $\begin{array}{l}\text { Fontana y Macagnan } \\
\quad(2013)\end{array}$ & Brasil & $\begin{array}{l}\text { Empresas listadas } \\
\text { BOVESPA (varios } \\
\text { sectores) }\end{array}$ & & & + \\
\hline Herrera (2013) & $\begin{array}{l}\text { Brasil y } \\
\text { España }\end{array}$ & Bancos & & & - \\
\hline
\end{tabular}

Fuente: elaboración propia de las autoras.

Donde: $I=$ índice; $j=$ banco; $i=$ indicadores $« i »$ del banco $\ll j » ; \chi_{i j}=$ número de indicadores $« i »$ obtenidos para el banco «j»; 1 si el ítem es revelado, 0 si no es revelado; de modo que $0 \leq I j \leq 1$; $n j=$ número de indicadores $=19$.

Los datos fueron obtenidos de cada uno de los informes anuales de los bancos que integran la muestra. Para ello se construyó una matriz para cada uno de los bancos. En esta, se anotaron los 19 indicadores para medir la revelación de los recursos intangibles relativos a capital estructural organizativo, y los respectivos años de estudio. Luego se divide el valor total de los ítems para cada banco entre el número máximo de los mismos que se puede lograr. Así se obtiene el porcentaje de revelación para cada uno de los indicadores.

Las variables explicativas están representadas por características de las organizaciones, que podrían están influyendo en la revelación de información sobre capital estructural organizativo. En la tabla 2 se presentan las hipótesis, las variables, las fórmulas y las unidades utilizadas.

En el caso de esta investigación, se utilizó el real brasilero como moneda estándar para mostrar los datos en cuanto al tamaño y dividendos por acción, debido a que la mayor parte de la muestra está integrada por bancos de Brasil. Además, el real es una moneda más antigua que el euro. Para ello, se utilizó el tipo de cambio promedio de cada año de las diferentes monedas, en relación con el real brasilero.

La ecuación (2) presenta el modelo empírico utilizado para analizar la relación estadística entre las características de los bancos estudiados y su respectivo nivel de revelación de información representativa del capital estructural organizativo.

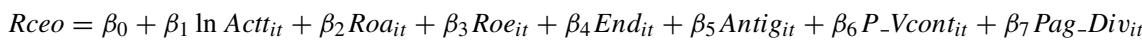

$$
\begin{aligned}
& +\beta_{8} E m_{-} N u_{-} A c c_{i t}+\beta_{9} D_{i v}{ }_{-} A c c_{i t}+\beta_{10} C_{o t}{ }_{-}{ }_{-} B_{o l} l_{i t}+\beta_{11} C_{-} A c t t_{i t}+\beta_{12} C_{-} I_{n g} g_{i t}+\beta_{13} C L u c_{i t}+\varepsilon_{i t}
\end{aligned}
$$

Siendo: $R$ ceo $=$ nivel de revelación capital estructural organizativo; $\beta_{0}=$ constante; $\beta_{i}=$ parámetros que serán estimados; $\ln A c t t_{i t}=$ total del activo del banco «i» en el año «t»; $R o a_{i t}=$ rentabilidad del activo del banco $\ll i »$ en el año $\left\langle t » ; R o e_{i t}=\right.$ rentabilidad del patrimonio del banco $\ll i »$ en el año «t»; $E_{n d} d_{i t}=$ endeudamiento del banco «i» en el año «t»; Antig $_{i t}=$ antigüedad del banco «i» en el año «t»; $P_{-} V c o n t_{i t}=$ precio de la acción dividido entre su valor contable del banco «i» en el año «t»; Pag Divit = dividendos pagados del banco «i» en el año «t»; $E m \_N u A c c_{i t}=$ emisión de nuevas acciones del banco $\ll i »$ en el año $« t » ; D i v \_A c c_{i t}=\operatorname{dividendos}$ por 
Tabla 2

Hipótesis, variables, identificación, fórmulas y unidades utilizadas

\begin{tabular}{|c|c|c|c|c|}
\hline Hipótesis & Variables & Identificación & Fórmulas & Unidades utilizadas \\
\hline Tamaño & Total de activos & Lnactt & Valor total del activo & Millones de reales \\
\hline \multirow[t]{2}{*}{ Rentabilidad } & Roa & Roa & (Utilidad neta/Activos)*100 & Porcentual \\
\hline & Roe & Roe & $\begin{array}{l}\text { (Utilidad neta/Patrimonio } \\
\text { líquido)*100 }\end{array}$ & Porcentual \\
\hline Endeudamiento & Endeudamiento & End & $\begin{array}{l}\text { (Total de pasivos/Total de } \\
\text { activos)*100 }\end{array}$ & Porcentual \\
\hline Antigüedad & $\begin{array}{l}\text { Años de constitución } \\
\text { del banco }\end{array}$ & Antig & $\begin{array}{l}\text { Años de constitución del } \\
\text { banco }\end{array}$ & Años \\
\hline $\begin{array}{l}\text { Precio de la acción } \\
\text { dividido por su } \\
\text { valor contable }\end{array}$ & $\begin{array}{l}\text { Precio de la acción } \\
\text { dividido por su valor } \\
\text { contable }\end{array}$ & P_Vcont & $\begin{array}{l}\text { (Cotización de la } \\
\text { acción/Valor contable de la } \\
\text { acción)*100 }\end{array}$ & Porcentual \\
\hline Pago de dividendos & Pago de dividendos & Pag_Div & Pago de dividendos & Dicotómica \\
\hline $\begin{array}{l}\text { Emisión de nuevas } \\
\text { acciones }\end{array}$ & $\begin{array}{l}\text { Emisión de nuevas } \\
\text { acciones }\end{array}$ & Em_Nu_Acc & Emisión de nuevas acciones & Dicotómica \\
\hline Dividendo por acción & Dividendo por acción & Div_Acc & Dividendo por acción & Reales \\
\hline $\begin{array}{l}\text { Cotización en más de } \\
\text { una bolsa }\end{array}$ & $\begin{array}{l}\text { Cotización en más de } \\
\text { una bolsa }\end{array}$ & $\mathrm{Cot}_{-}+\mathrm{Bol}_{1}$ & $\begin{array}{l}\text { Cotización en más de una } \\
\text { bolsa }\end{array}$ & Dicotómica \\
\hline \multirow[t]{3}{*}{ Crecimiento } & Activo total & C_Actt & $\begin{array}{l}\text { (Activo total del año } \\
\text { analizado/activo total del año } \\
\text { anterior)*100 }\end{array}$ & Porcentual \\
\hline & Ingresos & C_Ing & $\begin{array}{l}\text { (Ingresos del año } \\
\text { analizado/ingresos del año } \\
\text { anterior)*100 }\end{array}$ & Porcentual \\
\hline & Lucro líquido & C_Luc & $\begin{array}{l}\text { (Lucro líquido del año } \\
\text { analizado/Lucro líquido del } \\
\text { año anterior)*100 }\end{array}$ & Porcentual \\
\hline
\end{tabular}

Fuente: elaboración propia de las autoras.

acción del banco «i» en el año «t»; Cot $_{-}+B_{\text {Bol }} l_{i t}=$ cotización en más de una bolsa del banco «i»en el año «t»; $C \_$Actt $t_{i t}=$ crecimiento del activo total del banco $\ll i » e n$ el año $« t » ; C \_I n g_{i t}=$ crecimiento de los ingresos del banco «i»en el año «t»; $C L L u c_{i t}=$ crecimiento del lucro líquido del banco «i» en el año «t»; $\varepsilon_{i t}=$ error aleatorio que capta el efecto de las variables omitidas del banco $\ll i »$ en el año $« t » ; i=$ bancos, de 1 a 27; $t=$ años, de 2006 a 2011.

En este estudio fueron seleccionados los bancos inscritos en el mercado de capitales: en Brasil, la bolsa de São Paulo-BM\&F BOVESPA, y en España las bolsas de Madrid y Barcelona. La muestra la integran aquellos bancos que publicaron el $100 \%$ de sus informes anuales disponibles para descargar su página electrónica de Internet (38 bancos). Fueron eliminados 9 de ellos, debido a la ausencia de datos sobre algunas variables. La muestra quedó integrada por 29 bancos. Esta representa un total de 174 informes anuales. Esta muestra fue considerada para el análisis de las estadísticas descriptivas.

Para el cálculo de las regresiones fueron eliminados adicionalmente 2 bancos, uno de Brasil y uno de España, debido a que uno cotizaba en las bolsas de valores de ambos países y el otro era una subsidiaria, por lo cual se podrían comprometer los resultados. La muestra quedó integrada finalmente por 27 bancos y representa un total de 162 informes anuales. Para el desarrollo de esta investigación fueron analizados 6 años, desde el 2006 hasta el 2011. La muestra se presenta en la tabla 3 . 
Tabla 3

Bancos de la muestra por país

\begin{tabular}{|c|c|c|}
\hline N. ${ }^{o}$ & Banco & País \\
\hline 1 & Alfa Holdings, S.A. & Brasil \\
\hline 2 & Banestes, S.A.-Banco Est. Espiritu Santo & Brasil \\
\hline 3 & Banco ABC Brasil, S.A. & Brasil \\
\hline 4 & Banco Amazonia, S.A. & Brasil \\
\hline 5 & Banco Bradesco, S.A. & Brasil \\
\hline 6 & Banco Brasil, S.A. & Brasil \\
\hline 7 & Banco Daycoval, S.A. & Brasil \\
\hline 8 & Banco Estado do Río Grande do Sul, S.A. & Brasil \\
\hline 9 & Banco Industrial e Comercial, S.A. & Brasil \\
\hline 10 & Banco Indusval, S.A. & Brasil \\
\hline 11 & Banco Mercantil do Brasil, S.A. & Brasil \\
\hline 12 & Banco Nordeste do Brasil, S.A. & Brasil \\
\hline 13 & Banco Pine, S.A. & Brasil \\
\hline 14 & Banco Sofisa, S.A. & Brasil \\
\hline 15 & Consorcio Alfa de Administraçao, S.A. & Brasil \\
\hline 16 & Itau Unibanco Holding, S.A. & Brasil \\
\hline 17 & Itausa Investimentos Itau, S.A. & Brasil \\
\hline 18 & Banco Bilbao Vizcaya Argentaria, S.A. & España \\
\hline 19 & Banco de Chile & España \\
\hline 20 & Banco de Sabadell, S.A. & España \\
\hline 21 & Banco Español de Crédito, S.A. & España \\
\hline 22 & Banco Popular Español, S.A. & España \\
\hline 23 & Banco Santander, S.A. & España \\
\hline 24 & Bankinter, S.A. & España \\
\hline 25 & Bbva Banco Francés & España \\
\hline 26 & Caixabank, S.A. & España \\
\hline 27 & Grupo Financiero Banorte S.A.B de C.V. & España \\
\hline
\end{tabular}

Fuente: elaboración propia de las autoras.

\section{Resultados}

En esta sección se presentan los resultados obtenidos en esta investigación. Primero las estadísticas descriptivas, a continuación el análisis de correlación entre las variables explicativas, y finalmente el análisis de regresión.

\section{Análisis descriptivo y de correlaciones}

En esta sección se presentan las estadísticas descriptivas por país. En la tabla 4 se muestra la estadística descriptiva de la revelación de capital estructural organizativo de los bancos inscritos en la bolsa de valores de São Paulo-BM\&F BOVESPA.

Para el año 2008 se presenta el mayor porcentaje de la media con un $51.46 \%$, y el menor porcentaje se muestra para el año 2011, con un 39.77\%. Sin embargo, se observa que los porcentajes se mantienen muy cercanos. De acuerdo a los resultados presentados en la tabla 4 , se observa que los bancos de Brasil presentan un porcentaje de un 5.26\% como mínimo de revelación durante los 5 años de estudio. Esto genera como resultado una media de alrededor del 46\%, la cual es relativamente baja en cuanto a la revelación de información sobre capital estructural organizativo 
Tabla 4

Estadísticas descriptivas de la revelación de capital estructural organizativo de los bancos inscritos en la bolsa de valores de São Paulo-BM\&F BOVESPA

\begin{tabular}{llllll}
\hline Año & $\mathrm{N}$ & Media & DE & Mínimo & Máximo \\
\hline 2006 & 18 & 42.11 & 23.40 & 5.26 & 84.21 \\
2007 & 18 & 45.61 & 22.11 & 5.26 & 78.95 \\
2008 & 18 & 51.46 & 24.59 & 5.26 & 78.95 \\
2009 & 18 & 49.42 & 27.15 & 5.26 & 84.21 \\
2010 & 18 & 48.83 & 23.87 & 5.26 & 78.95 \\
2011 & 18 & 39.77 & 23.20 & 5.26 & 78.95 \\
\hline
\end{tabular}

Fuente: elaboración propia de las autoras en base a la información presentada en los informes anuales publicados por los bancos inscritos en la bolsa de valores de São Paulo-BM\&F BOBESPA, el 2 de junio de 2012.

Tabla 5

Resumen de las estadísticas descriptivas de la revelación de capital estructural organizativo por los bancos inscritos en las bolsas de Madrid y Barcelona

\begin{tabular}{llllll}
\hline Año & N & Media & DE & Mínimo & Máximo \\
\hline 2006 & 11 & 73.21 & 11.15 & 52.63 & 84.21 \\
2007 & 11 & 71.29 & 12.54 & 52.63 & 89.47 \\
2008 & 11 & 69.38 & 9.94 & 52.63 & 78.95 \\
2009 & 11 & 71.29 & 10.62 & 52.63 & 84.21 \\
2010 & 11 & 69.38 & 12.41 & 42.11 & 84.21 \\
2011 & 11 & 58.37 & 16.88 & 26.32 & 78.95 \\
\hline
\end{tabular}

Fuente: elaboración propia, en base a la información presentada en los informes anuales publicados por los bancos inscritos en las bolsas de Madrid y Barcelona, el 2 de junio de 2012.

por parte de los bancos brasileros. Dado que el máximo de revelación se encuentra entre el 78 y el $84 \%$, la desviación estándar es bastante significativa.

En la tabla 5 se muestra la estadística descriptiva de la revelación de capital estructural organizativo de los bancos inscritos en las bolsas de Madrid y Barcelona.

De acuerdo a los resultados de la tabla 5, al comparar con los resultados de Brasil, los bancos españoles en media revelan más informaciones sobre su capital estructural organizativo. Además, los resultados muestran que existe un porcentaje de desviación estándar inferior al presentado en los resultados de los bancos brasileños; esto es debido al hecho de que el porcentaje mínimo de revelación se incrementó significativamente, sin embargo el nivel máximo de revelación es muy próximo para ambos países.

La tabla 6 muestra las estadísticas descriptivas de las variables explicativas.

La variable total de activos muestra la existencia de una elevada desviación estándar en cuanto al tamaño de los bancos, encontrándose dentro de la muestra bancos muy grandes y muy pequeños. En cuanto a la eficacia para lograr utilidades a través de los activos, se observa una rentabilidad en promedio del $1.54 \%$, y algunos bancos de la muestra reflejan porcentajes negativos de rentabilidad. En cuanto a la rentabilidad del patrimonio, se observa una media aceptable, lo que indica un buen rendimiento de la inversión de los propietarios.

A través de la variable antigüedad se observa que en la muestra existen bancos relativamente jóvenes, así como bancos con siglos de existencia. La relación precio de la acción/valor contable muestra que en promedio las acciones están en un $0.49 \%$ por encima de su valor contable. En cuanto los dividendos pagados por acción, se observa una desviación estándar del $0.63 \%$, con pago máximo de 3.49 y un mínimo de 0 . En cuanto a las variables crecimiento del activo, de los 
Tabla 6

Estadísticas descriptivas de las variables explicativas

\begin{tabular}{llccrr}
\hline Variables explicativas & $\mathrm{N}$ & Media & DE & Mínimo & Máximo \\
\hline Actt & 161 & $287,000,000$ & $575,000,000$ & $1,120,649$ & $3,080,000,000$ \\
Roa & 161 & 1.54 & 0.85 & -0.70 & 4.50 \\
Roe & 161 & 15.49 & 7.65 & -5.10 & 41.40 \\
End & 161 & 89.15 & 5.99 & 67.07 & 97.40 \\
Antig & 161 & 75.00 & 45.00 & 9.00 & 203.00 \\
P_Vcont & 161 & 1.49 & 1.04 & 0.00 & 4.96 \\
Pag_Div & 161 & 0.88 & 0.32 & 0.00 & 1.00 \\
Em_Nu_Acc & 161 & 0.43 & 0.50 & 0.00 & 1.00 \\
Div_Acc & 161 & 0.62 & 0.63 & 0.00 & 3.49 \\
Cot_+_Bol & 161 & 0.48 & 0.50 & 0.00 & 1.00 \\
C_Actt & 161 & 21.50 & 40.27 & -55.25 & 430.39 \\
C_Ing & 161 & 15.72 & 28.33 & -92.52 & 120.17 \\
C_Luc & 161 & 20.89 & 76.57 & -209.31 & 616.98
\end{tabular}

Fuente: elaboración propia de las autoras.

Tabla 7

Matriz de correlaciones de las variables explicativas

\begin{tabular}{|c|c|c|c|c|c|c|c|c|c|c|c|c|c|}
\hline Variables & 1 & 2 & 3 & 4 & 5 & 6 & 7 & 8 & 9 & 10 & 11 & 12 & 13 \\
\hline 1. Actt & 1.00 & & & & & & & & & & & & \\
\hline 2. Roa & -0.28 & 1.00 & & & & & & & & & & & \\
\hline 3. Roe & -0.01 & 0.52 & 1.00 & & & & & & & & & & \\
\hline 4. End & 0.35 & -0.55 & 0.32 & 1.00 & & & & & & & & & \\
\hline 5. Antig & 0.54 & -0.26 & 0.16 & 0.40 & 1.00 & & & & & & & & \\
\hline 6. P_Vcont & 0.06 & 0.12 & 0.55 & 0.29 & 0.25 & 1.00 & & & & & & & \\
\hline 7. Pag_Div & 0.16 & -0.20 & 0.16 & 0.45 & 0.28 & 0.17 & 1.00 & & & & & & \\
\hline 8. Em_Nu_Acc & 0.29 & -0.10 & 0.19 & 0.29 & 0.17 & 0.32 & 0.24 & 1.00 & & & & & \\
\hline 9. Div_Acc & 0.46 & -0.17 & 0.15 & 0.38 & 0.35 & 0.18 & 0.18 & 0.13 & 1.00 & & & & \\
\hline 10. $\mathrm{Cot}_{-}+$Bol & 0.45 & -0.25 & 0.14 & 0.47 & 0.49 & 0.24 & 0.28 & 0.48 & 0.24 & 1.00 & & & \\
\hline 11. C_Actt & -0.02 & 0.03 & 0.02 & -0.01 & -0.15 & 0.07 & 0.01 & 0.18 & -0.08 & -0.01 & 1.00 & & \\
\hline 12. C_Ing & -0.11 & 0.24 & 0.14 & -0.14 & -0.18 & 0.03 & -0.06 & 0.06 & -0.06 & -0.15 & 0.22 & 1.00 & \\
\hline 13. C_Luc & -0.09 & 0.33 & 0.27 & -0.13 & -0.10 & 0.10 & -0.22 & -0.03 & -0.03 & -0.13 & 0.01 & 0.17 & 1.00 \\
\hline
\end{tabular}

Fuente: elaboración propia de las autoras.

ingresos y del lucro líquido, se observa que la mayor desviación estándar la muestra la variable crecimiento del lucro líquido, con el $76.57 \%$, mostrando así bancos con alto crecimiento de sus utilidades y otros con pérdidas significativas.

Para la variable total de activos se sugiere la transformación de los datos originales en logaritmo o raíz cuadrada a fin de facilitar el trabajo estadístico. Para el resto de las variables explicativas se ajustó cada variable a menos uno, con el mismo ajuste para cada variable, es decir ajustada al período anterior, a fin de lograr resultados favorables para el modelo de regresión. La tabla 7 presenta los coeficientes de correlación entre las variables explicativas.

La variable activo total está relativamente correlacionada con la variable antigüedad. La variable Roa está relativamente correlacionada con la variable Roe y con la variable endeudamiento. La variable Roe está relativamente relacionada con la variable precio entre el valor contable. Sin embargo estas correlaciones no son tan fuertes como para que exista la necesidad de eliminar 
Tabla 8

Resultados del modelo de regresión

Variable dependiente: Rceo

Método de mínimos cuadrados

Muestra (ajustada): 2162

Observaciones incluidas: 155 después del ajuste

\begin{tabular}{|c|c|c|c|c|}
\hline Variables & Coeficientes & Error estándar & Estadístico t & Probabilidad \\
\hline Actt & 6.679738 & 0.887045 & 7.530327 & $* 0.0000$ \\
\hline $\operatorname{Roa}(-1)$ & 12.63953 & 4.145305 & 3.049119 & *0.0027 \\
\hline $\operatorname{Roe}(-1)$ & -1.306647 & 0.438270 & -2.981375 & *0.0034 \\
\hline Endeud $(-1)$ & 0.843886 & 0.565902 & 1.491223 & 0.1381 \\
\hline $\operatorname{Antig}(-1)$ & 0.060520 & 0.037410 & 1.617738 & 0.1080 \\
\hline$P_{-}$V cont $(-1)$ & 2.438189 & 1.785499 & 1.365551 & 0.1743 \\
\hline $\operatorname{Pag} \_\operatorname{Div}(-1)$ & -3.946226 & 4.707046 & -0.838366 & 0.4032 \\
\hline Em_Nu_Acc $(-1)$ & -2.715986 & 3.365213 & -0.807077 & 0.4210 \\
\hline Div_Acc $(-1)$ & 2.623013 & 2.418655 & 1.084493 & 0.2800 \\
\hline Cot__+_Biol $(-1)$ & 3.448765 & 4.846960 & 0.711531 & 0.4779 \\
\hline C_Actt $(-1)$ & -0.116804 & 0.063346 & -1.843906 & $* * 0.0673$ \\
\hline C_Ing $(-1)$ & -0.025201 & 0.051500 & -0.489331 & 0.6254 \\
\hline C_Luc $(-1)$ & -0.010332 & 0.019295 & -0.535500 & 0.5931 \\
\hline $\mathrm{C}$ & -142.7817 & 53.84249 & -2.651841 & 0.0089 \\
\hline R-cuadrado & 0.537739 & \multicolumn{2}{|c|}{ Estadístico F } & 12.61709 \\
\hline \multirow[t]{2}{*}{ R-cuadrado ajustado } & 0.495119 & \multicolumn{2}{|c|}{ Probabilidad (estadístico F) } & 0.000000 \\
\hline & & \multicolumn{2}{|c|}{ Durbin-Watson } & 2.015438 \\
\hline
\end{tabular}

* $\mathrm{p}<0.01$.

** $\mathrm{p}<0.10$.

Fuente: elaboración propia de las autoras.

alguna de las variables explicativas. Con relación a las demás variables, se observan diferentes correlaciones en menor significación. Seguidamente se presenta el modelo de regresión.

\section{Análisis de regresión}

En esta sección se presentan los resultados del modelo de regresión, a través del método de mínimos cuadrados con datos de panel. La tabla 8 muestra las hipótesis que fueron contrastadas como características de los bancos para revelar informaciones sobre capital estructural organizativo.

En la tabla 8 también se presenta el modelo de regresión, a través de método de mínimos cuadrados con datos de panel. Se analizan todas las hipótesis, sin embargo, como puede observarse la mayoría de las variables muestran baja significación. La tabla 9 presenta el modelo de regresión, donde fueron eliminadas algunas variables que no mostraban significación.

Tal como se muestra en el modelo, fueron eliminadas las variables precio/valor contable, pago de dividendos, emisión de nuevas acciones, dividendos por acción, cotización en más de una bolsa, crecimiento de los ingresos y crecimiento del lucro líquido, porque su nivel de significación no aportaba nada al modelo, afectando los niveles del resto de las variables.

En este modelo el estadístico $\mathrm{F}$ indica que el grado de probabilidad es muy bueno, con el $100 \%$ de significación (0.000000). El estadístico Durbin-Watson muestra que los residuos son independientes. Este modelo no presenta problemas de autocorrelación, de acuerdo a los resultados del test de correlación LM. 
Tabla 9

Resultados finales del modelo. Se incluyen sólo las variables con mayor significancia

\begin{tabular}{|c|c|c|c|c|}
\hline & Observac & $\begin{array}{l}\text { le dependiente: } \\
\text { de mínimos cua } \\
\text { tra (ajustada): } 2 \\
\text { cluidas: } 161 \text { de }\end{array}$ & ajuste & \\
\hline Variables & Coeficientes & Error estándar & Estadístico t & Probabilidad \\
\hline Actt & 6.681018 & 0.646945 & 10.32703 & $* 0.0000$ \\
\hline $\operatorname{Roa}(-1)$ & 11.29810 & 3.870802 & 2.918802 & $* 0.0040$ \\
\hline $\operatorname{Roe}(-1)$ & -1.073272 & 0.384703 & -2.789872 & $* 0.0059$ \\
\hline Endeud(-1) & 0.779866 & 0.494046 & 1.578530 & 0.1165 \\
\hline Antig(-1) & 0.079727 & 0.032457 & 2.456378 & $* * 0.0151$ \\
\hline C_Actt $(-1)$ & -0.125323 & 0.055530 & -2.256851 & $* * 0.0254$ \\
\hline $\mathrm{C}$ & -138.5555 & 45.20376 & -3.065133 & 0.0026 \\
\hline R-cuadrado & 0.504877 & & Estadístico F & 26.17233 \\
\hline R-cuadrado ajustado & 0.485587 & Proba & (estadístico F) & 0.000000 \\
\hline & & & Irbin-Watson & 1.904847 \\
\hline
\end{tabular}

${ }^{*} \mathrm{p}<0.01$.

** $\mathrm{p}<0.05$.

Fuente: elaboración propia de las autoras.

\begin{tabular}{lclr}
\hline Breusch-Godfrey Serial Correlation LM Test: & & \\
Estadístico F & 0.702680 & Prob. F(2,152) & 0.4969 \\
Obs*R-cuadrado & 1.474935 & Prob. Chi-cuadrado(2) & 0.4783 \\
\hline
\end{tabular}

En conjunto, las variables explican en un $48.56 \%$ la varianza de la variable dependiente. Como resultado, se confirmaron 5 variables, como características que motivan la revelación voluntaria de información sobre recursos intangibles relativos a capital estructural organizativo.

Las hipótesis tamaño, Roa y Roe fueron confirmadas con el 99\% de confianza (valor de $\mathrm{p}<0.01)$.

La hipótesis tamaño, representada por la variable total de activos, fue confirmada con relación positiva, es decir que cuanto mayor sea el tamaño de los activos del banco, mayor sería la revelación de información representativa de su capital estructural organizativo. Estos resultados ratifican los obtenidos por Carnaghan (1999), Gray et al. (2001), Arvidsson (2003), Bozzolan et al. (2003), Rodríguez (2004), García-Meca et al. (2005), Macagnan (2005), Macagnan y Rodríguez (2005), Macagnan (2007, 2009), Vikalpa (2012) y Herrera (2013).

La hipótesis rentabilidad, representada por la variable Roa fue confirmada con relación positiva, es decir que cuanto más rentables sean los activos del banco, mayor sería la revelación de información representativa de su capital estructural organizativo. Las mismas conclusiones fueron obtenidas por Rodríguez (2004), Vikalpa (2012) y Herrera (2013).

Por otra parte, la variable Roe fue confirmada con relación negativa. Es decir que cuanto mayor sea la capacidad de la empresa para remunerar a sus accionistas, menor sería el interés de los bancos en Brasil y España por revelar informaciones representativas de su capital estructural organizativo. Ratifican estos resultados los obtenidos por Macagnan (2007) y Vikalpa (2012).

La hipótesis antigüedad también fue confirmada para este modelo; esta con un 95\% de confianza (valor de $\mathrm{p}<0.05$ ). Esta hipótesis fue confirmada con relación positiva. Significa esto que cuanto más antiguo sea el banco, mayor sería la revelación de informaciones de recursos 
intangibles representativos de capital estructural organizativo. Con los mismos resultados concluyeron Macagnan (2007, 2009) y Herrera (2013) sus investigaciones.

La hipótesis crecimiento, con la variable crecimiento del activo total, fue confirmada con relación negativa; esta con el $95 \%$ de confianza (valor de $\mathrm{p}<0.05$ ). Es decir que cuanto mayor sea el crecimiento de los activos del banco, menor sería la revelación de informaciones sobre capital estructural organizativo. El resto de las hipótesis fueron rechazadas como características que motivan la revelación de información sobre capital estructural organizativo.

\section{Consideraciones finales}

La revelación de información voluntaria es una práctica cada vez más utilizada por las organizaciones. En especial por aquellas que utilizan el mercado de capitales para financiarse. Fueron analizadas las organizaciones bancarias inscritas en las bolsas de valores: de Brasil y de España. Se revisaron los informes anuales de 29 bancos inscritos en el mercado de capitales de estos países. Las empresas que cotizan en el mercado español revelan mayor cantidad de informaciones de recursos intangibles relativos a capital estructural organizativo que las empresas que cotizan en el mercado de valores de Brasil, según los resultados obtenidos en las estadísticas descriptivas. Los valores de la media en cuanto a revelación de información de este tipo de recursos intangibles por parte de los bancos que cotizan en España casi duplican los valores de la media de los bancos que cotizan en Brasil.

En cuanto a las características que motivan la revelación voluntaria sobre intangibles representativos de capital estructural organizativo, los resultados muestran que cuanto mayor sea el tamaño de los bancos, más antiguos sean y mayor la rentabilidad de sus activos, mayor será la revelación de informaciones de recursos intangibles relativos a capital estructural organizativo. Estos resultados ratifican los presupuestos de la teoría de la agencia (Jensen y Meckling, 1976), que plantea que mientras más grande sea el tamaño de la empresa, más antigua, y cuanto más rentables sean sus activos, mayor debería ser la revelación de informaciones representativas del capital estructural organizativo.

Las hipótesis rentabilidad del patrimonio y crecimiento del activo total fueron confirmadas con relación negativa. Estos resultados ratifican los presupuestos de la teoría del coste del propietario (Verrecchia, 1983; Macagnan, 2007), que plantea que mientras más rentables sean las empresas y mayor sea su crecimiento, menor debería ser la revelación de sus recursos intangibles representativos de capital estructural organizativo, ya que estaría incurriendo en costes innecesarios.

Este estudio constituye un gran aporte al analizar mercados de capitales de 2 países diferentes: Brasil y España. Se puede observar la diferencia en cuanto a revelación de capital estructural organizativo por parte de estas organizaciones, a pesar de que el mercado de capitales es para estos una muy importante fuente de recursos. Es importante resaltar que en estos países también existen marcadas diferencias tanto legales como de niveles de gobernanza corporativa, sumado a la cultura propia de cada uno de estos mercados financieros.

El informe anual es el único medio de revelación de información considerado en esta investigación; sin embargo, las organizaciones bancarias que integran el mercado de capitales de estos países podrían utilizar otros medios para comunicar este tipo de informaciones a los interesados.

En este estudio solo se analiza la revelación voluntaria de recursos intangibles relativos a capital estructural organizativo. Sería importante hacer una comparación con otros índices de revelación, que podrían permitir conocer la importancia que las organizaciones bancarias dan a otros indicadores de recursos intangibles. 
No se trata de un abordaje comparativo entre estos 2 países, solo se analiza la correlación entre la divulgación de información de capital estructural organizativo y las características que pudieran condicionar la misma.

\section{Anexo 1. Indicadores voluntarios representativos de capital estructural organizativo (19 ítems)}

Cifras que indiquen el nivel de informatización de la empresa (n. ${ }^{\circ \circ}$ ordenadores, otros)

Datos sobre el sistema de información (bases de datos, personal con acceso a ordenadores)

Personal dedicado a tecnologías de información

Mejoras introducidas en los procesos/organización en el período

Costos de las mejoras introducidas en los procesos/organización en el período

Razones para las inversiones en los procesos de información

Sistemas de gestión y control utilizados

Cifras de distribución y/u organización de tiempos de trabajo

Trabajadores con alto nivel de autonomía para realizar su trabajo

Declaración de la cultura organizativa

Política de comunicación interna

Estructura organizativa/organigrama de la empresa

Historial y evolución de la empresa (años de constitución)

Línea estratégica básica

Posición competitiva de la empresa en el sector

Pronósticos del sector

Comentario sobre amenazas de sustitutivos de la competencia (servicios de competidores)

Comentario sobre ventajas tecnológicas de la empresa

Comentario sobre fusiones o adquisiciones

Fuente: elaboración propia de las autoras.

\section{Referencias}

Adiloğlu, B. y Vuran, B. (2012). The relationship between the financial ratios and transparency levels of financial information disclosures within the scope of corporate governance: Evidence from Turkey. Journal of Applied Business Research, 28(4), 543-554.

Akerlof, G. A. (1970). The market for lemons: Quality uncertainty and the market mechanism. Quarterly Journal of Economics, 84(3), 488-500.

Arvidsson, S. (2003). The extent of disclosure on intangibles in annual reports. Working paper, 4th annual SNEE congress in Mölle.

Babío, M. R., Muíño, M. F. y Vidal, R. (2003). La actitud de las empresas cotizadas ante la presentación de la información voluntaria. Una referencia a la naturaleza de la información. Revista Europea de Dirección y Economía de la Empresa, 12(4), 49-68.

Bhattachrya, N., Desai, H. y Venkataraman, K. (2013). Does Earnings Quality Affect Information Asymmetry? Eviddence from Trading Costs. Contemporary Accounting Research, 30(2), 482-516.

Boesso, G. y Kumar, K. (2007). Drivers of corporate voluntary disclosure: A framework and empirical evidence from Italy and the United States. Accounting, Auditing \& Accountability Journal, 20(2), 269-296.

Bozzolan, S., Favotto, F. y Ricceri, F. (2003). Italian annual intellectual capital disclosure: An empirical analysis. Journal of Intellectual Capital, 4(4), 543-558.

Bukh, P. N., Nielsen, C., Gormsen, P. y Mouritsen, J. (2005). Disclosure of information on intellectual capital in Danish IPO prospectuses. Accounting Auditing \& Accountability Journal, 18(6), 713-732. http://dx.doi.org/10.1108/09513570510627685

Buzby, S. L. (1975). Company size, listed versus unlisted stock, and the extent of financial disclosure. Journal of Accounting Research, 13(1), 16-37. 
Camfferman, K. y Cooke, T. E. (2002). An analysis of disclosure in the annual reports of U.K. and Dutch companies. Journal of International Accounting Research, 1, 3-30.

Carnaghan (1999). Factors influencing managerial decisions about intangible asset disclosures: The role of accountability theory and impression management. University of Alberta.

Clegg, S. (2010). The state, power and agency. Journal of Management Inquiry, 19, 4-13.

Cooke, T. E. (1989). Voluntary corporate disclosure by Swedish companies. Journal of International Financial Management \& Accounting, 1(2), 171-195.

Cooke, T. E. (1992). The impact of size, stock market listing and industry type on disclosure in the annual reports of Japanese listed corporations. Accounting \& Business Research, 22(87), 229-237.

Cuevas-Rodríguez, G., Gómez-Mejía, L. y Wiseman, R. (2012). Has agency theory run its course?: Making the theory more flexible to inform the management of reward systems. Corporate Governance: An International Review, 20(6), 526-546.

Dalton, D. R., Hitt, M. A., Certo, S. T. y Dalton, C. M. (2007). The fundamental agency problem and its mitigation: Independence, equity, and the market for corporate control. Academy of Management Annals, 1, 1-64.

Darrough, M. y Stoughton, N. (1990). Financial disclosure policy in an entry game. Journal of Accounting \& Economics, 12(1-3), 219-243.

Easley, D. y O'Hara, M. (2005). Information and the cost of capital. Journal of Finance, 59(4), 1553-1583.

Eisenhardt, K. M. (1989). Agency theory: An assessment and review. Academy of Management Review, 14, $157-174$.

Fama, E. F. y Jensen, M. C. (1983). Separation of ownership and control. Journal of Law and Economics, 26, 301-326.

Ferraz, C. L., Fernandes, A. H. y Louvet, P. (2011). Um índice de avaliação da qualidade da governança corporativa no Brasil. Revista Revista Contabilidade \& Finanças - USP, São Paulo, 22(55), 45-63.

Fishman, M. y Hagerty, L. (1989). Disclosure decisions by firms and the competition for price efficiency. The Journal of Finance, 44(3), 633-646.

Fontana, F.B. (2011). Fatores explicativos do nível de evidenciação voluntária de informações sobre recursos intangíveis das empresas listadas na BM\&F BOVESPA. Dissertação (mestrado)—Universidade do Vale do Rio dos Sinos, Programa de Pós-Graduação em Ciências Contábeis.

Fontana, F. y Macagnan, C. B. (2013). Factors explaining the level of voluntary human capital disclosure in the Brazilian capital market. Intangible Capital., 9(1), 305-321.

Fulghieri, P. y Suominen, M. (2012). Corporate governance, finance, and the real sector. Journal of Financial and Quantitative Analysis, 47(6), 1187-1214. http://dx.doi.org/10.1017/S0022109012000531

García-Meca, E., Parra, I., Larrán, M. y Martínez, I. (2005). The explanatory factors of intellectual capital disclosure to financial analysts. European Accounting Review, 14(1), 63-94.

Gazda, V., Maliková, Z., Kubák, M. y Gróf, M. (2012). Double oral auctions and tendencies toward moral hazard. Annals of the University of Oradea, Economic Science Series, 21(2), 207-213.

Gelb, D. S. (2002). Intangible assets and firms' disclosures: An empirical investigation. Journal of Business Finance \& Accounting, 29(3), 457-476.

Gershkov, A. y Perry, M. (2012). Dynamic contracts with moral hazard and adverse selection. Review of Economic Studies, 79(1), 268-306. http://dx.doi.org/10.1093/restud/rdr026

Gómez-Mejía, L. R., Berrone, P. y Franco-Santos, M. (2010). Compensation and organizational performance. Armonk, NY: M.E. Sharpe.

Gopalan, R., Udell, G. F. y Yerramilli, V. (2011). Why do firms form new banking relationships? Journal of Financial and Quantitative Analysis, 46(5), 1335-1365. http://dx.doi.org/10.1017/S0022109011000299

Gray, R., Javad, M., Power, D. M. y Sinclair, C. (2001). Social and environmental disclosure and corporate characteristics: A research note and extension. Journal of Business Finance \& Accounting, 28(3/4), 327-356.

Gray, S. J., Radebaugh, L. H. y Roberts, C. B. (1990). International perceptions of cost constraints on voluntary information disclosures: A comparative study of U.K. and U.S. multinationals. Journal of International Business Studies, 21(4), 597-622.

Healy, P. M. y Palepu, K. G. (2001). Information asymmetry, corporate disclosure and capital markets: A review of the empirical disclosure literature. Journal of Accounting and Economics., 31(1-3), 405-440.

Hermalin, B. E. y Weisbach, M. S. (2003). Boards of directors as an endogenously determined institution: A survey of the economic literature. Economic Policy Review, 9, 7-26.

Herrera R., E. E. (2013). Revelación voluntaria de los recursos intangibles de los bancos: Panamá, Brasil y España y sus factores explicativos. Tesis doctoral. Universidad de Panamá.

Hidalgo, G. R. y García, M. E. (2009). Divulgación de información sobre el capital intelectual de empresas nacionales que cotizan en la Bolsa Mexicana de Valores. Revista Contaduría y Administración, 229, 105-131. 
Hyderabad, R. L. (2013). Are share repurchases substitutes for dividend payments in India? IUP Journal of Applied Finance, 19(1), 27-50.

Jensen, M. C. y Meckling, W. H. (1976). Theory of the firm: Managerial behavior, agency costs and ownership structure. Journal of Financial Economics, 3(4), 305-360.

Joseph, J., Ocasio, W. y McDonnell, M. (2014). The structural elaboration of board independence executive power, institutional logics, and the adoption of CEO-only board structures in U.S. corporate governance. Academy of Management Journal, 57(6), 1834-1858. http://dx.doi.org/10.5465/amj.2012.0253

Kang, H. y Gray, S. J. (2011). The content of voluntary intangible asset disclosures: Evidence from emerging market companies. Journal of International Accounting Research, 10(1), 109-125.

Lan, L. y Heracleous, L. (2010). Rethinking agency theory: The view from law. Academy of Management Review, 35(2), 294-314.

Lev, B. (2004). Sharpening the intangibles edge. Harvard Business Review, 82(6), 109-116.

Macagnan, C.B. (2005). Factores explicativos de la revelación de información de activos intangibles de empresas que cotizan en España. Trabajo de investigación-Universidad Autónoma de Barcelona.

Macagnan, C.B. (2007). Condicionantes e Implicación de Revelar Activos Intangibles. Tesis doctoral. Universidad Autónoma de Barcelona. Departamento de Economía de la Empresa.

Macagnan, C. B. (2009). Evidenciação voluntária: fatores explicativos da extensão da informação sobre recursos intangíveis. Revista Contabilidade \& Finanças, USP, São Paulo., 20(50), 46-61.

Macagnan, C. B. y Rodríguez, (2005). The intellectual capital disclosed in the annual reports of the non-financial companies which quote in the Spanish stock exchange. Working paper. Business Association of Latin American Studies (BALAS). Annual Conference. Madrid (España).

Marr, B. y Gray, D. (2002). Measuring intellectual capital-The internal and external drivers for measuring and reporting the intangibles of an organization. In Conferencia The transparent enterprise, the value of intangibles Madrid.

Misangyi, V. F. y Acharya, A. G. (2014). Substitutes or complements? A configurational examination of corporate governance mechanisms. Academy of Management Journal, 57(6), 1681-1705. http://dx.doi.org/10.5465/AMJ.2012.0728

Prencipe, A. (2004). Proprietary costs and determinants of voluntary segment disclosure: Evidence from Italian listed companies. The European Accounting Review, 13(2), 319-340, 10.10800963818042000204742.

Raelin, J. D. y Bondy, K. (2013). Putting the good back in good corporate governance: The presence and problems of double-layered agency theory. Corporate Governance: An International Review, 21(5), 420-435.

Rodríguez, G. (2004). Factores explicativos de la revelación voluntaria de información sobre fuentes de ventaja competitiva empresarial. Revista Española de Financiación y Contabilidad, 33(122), 705-739.

Rodríguez, L., Gallego, L. y García, I. M. (2008). Determinantes de la divulgación voluntaria de información estratégica en internet: un estudio de las empresas españolas cotizadas. Revista Europea de Dirección y Economía de la Empresa, 19(1), 9-26.

Shleifer, A. y Vishny, R. W. (1997). A survey of corporate governance. Journal of Finance, 52, 737-783.

Singhvi, S. y Desay, H. (1971). An empirical analysis of the quality of corporate financial disclosure. The Accounting Review, 46(1), 129-138.

Subramanian, S. R. y Nagi, V. (2010). Voluntary disclosures and international product market. Decision, 37(2), 31-50.

Verrecchia, R. E. (1983). Discretionary disclosure. Journal of Accounting \& Economics, 5(3), 179-194.

Vikalpa, R. (2012). Corporate disclosure of intangibles: A comparative study of practices among Indian, US, and Japanese companies. The Journal for Decision Makers, 37(3), 51-72.

Wagenhofer, A. (1990). Voluntary disclosure with a strategic opponent. Journal of Accounting \& Economics, 12(4), 341-363.

Williams, S. M. (2001). Is intellectual capital performance and disclosure practices related? Journal of Intellectual Capital, 2(3), 192-203. 